\title{
Skin lesions caused by Orthopoxvirus in children
}

\author{
Katarzyna Mazur-Melewska', Ilona Pieczonka-Ruszkowska ${ }^{1,2}$, Krystyna Szpura' ${ }^{1}$, Agnieszka Myszkowska-Torz ${ }^{1}$, \\ Anna Mania ${ }^{1}$, Paweł Kemnitz ${ }^{1}$, Wojciech Służewski ${ }^{1}$, Magdalena Figlerowicz ${ }^{1}$
}

1Department of Infectious Diseases and Child Neurology, Poznan University of Medical Sciences, Poznan, Poland ${ }^{2}$ Department of Clinical Auxology and Paediatric Nursing, Poznan University of Medical Sciences, Poznan, Poland

Adv Dermatol Allergol 2020; XXXVII (5): 695-699 DOI: https://doi.org/10.5114/ada.2019.85366

\begin{abstract}
Introduction: The global eradication of smallpox and abandonment of mandatory smallpox vaccination has led to an increased proportion of the population who are immunologically naïve to infections caused by Orthopoxviruses (OPV).

Aim: To present the different courses of OPV infection in children and to highlight the diagnostic difficulties in their differentiation from the other inflammatory processes.

Material and methods: We retrospectively evaluated the medical documentation of 5 children with OPV infection. Clinical diagnosis of OPV infection was based on evaluation of animal contact and skin symptoms, characterised by either a single ulcer or disseminated lesions. In all five cases, blood samples and skin swabs were collected from the lesion(s) to identify specific OPV DNA fragments (Vgf, b9R and D11L genes) using PCR.

Results: Two children presented with high fever, a single ulcer on the skin and local lymphadenopathy. The three other patients were in good general health and their skin lesions presented as a disseminated vesicular rash. Using the Vgf gene as the target for PCR, OPV infection was confirmed in material collected from skin lesions of all children and in blood samples of 4 children. The B9R and d11L genes tested positive in the skin material of 2 children and blood samples of 2 children. All analysed patients presented a history of ineffective antibiotic therapy. Conclusions: In the case of unclear necrotising skin lesions in children, the primary diagnosis always includes bacterial dermatitis. However, if the patient has come into contact with animals, diagnosis of OPV infection should also be considered.
\end{abstract}

Key words: Orthopoxvirus, cowpox, children.

\section{Introduction}

The global eradication of smallpox and abandonment of mandatory smallpox vaccination has resulted in an increasing proportion of the population who are immunologically naïve to infections caused by Orthopoxvirus (OPV) [1].

Orthopoxvirus and Parapoxvirus, both genera belonging to the Poxviridae family, cause acute, exanthematic disease in humans and domestic animals [2]. Zoonotic OPV species, including monkeypox virus (MPXV), cowpox virus (CPXV), camelpox virus (CMPV) and vaccinia virus (VACV), have been associated with an increasing number of outbreaks worldwide [3]. The re-emergence of OPV infections has been observed in different regions of the world, including animal VACV, which is endemic in Asia (India) and South America, and MPXV, which occurs in African tropical rainforests. Additionally, CPXV has been reported in Europe, in both humans and animals, including dogs, cats, primates, elephants and various other zoo animals [4]. Wild rodents seem to be the primary hosts and reservoirs of CPXV, and hunting cats can be infected through their prey. The incidence of CPXV infection among domestic cats is high, estimated to be $2 \%$ in Germany, 4\% in Austria, 5\% in Denmark and 10.1\% in Norway $[5,6]$. While animal-to-human transmission is rare, there are reports of cases of zoonosis in the owners of infected animals. People usually acquire the infection via contact with infected cats or pet rats $[4,5,7]$. A typical CPXV infection manifests as a mild skin disease characterised by a single pock-like lesion, which heals within 3-6 weeks. The factors resulting in a severe, prolonged clinical course are not yet known. However, there have been reports of generalised disorders, and even death in 1 patient $[8,9]$.

Address for correspondence: Katarzyna Mazur-Melewska, Department of Infectious Diseases and Child Neurology, Poznan University of Medical Sciences, 27/33 Szpitalna St, 60-578 Poznań, Poland, phone: +48 6184913 62, e-mail: katarzynam-m@wp.pl Received: 27.10.2018, accepted: 28.02.2019. 


\section{Aim}

Our study aimed to present the different courses of OPV infection in children, and to highlight the diagnostic difficulties when differentiating from other inflammatory processes.

\section{Material and methods}

We retrospectively evaluated the medical documentation of 5 patients with OPV infection who were hospitalised in the Department of Infectious Diseases and Child Neurology at the University of Medical Sciences in Poznan, Poland, between 1 July 2015 and 1 February 2018. Data were collected from 5 patients aged 2 to 13 years ( $M=6.6 \pm 2.33$ years). The subjects included 4 boys and 1 girl (Table 1). All children were admitted with nonspecific skin lesions which were resistant to conventional antibacterial treatment.

\section{Diagnosis}

Clinical diagnosis of OPV infection was based on animal contact and skin symptoms, characterised by a single ulcer or disseminated atypical lesions on the body. All patients were examined by paediatricians during their hospitalisation. For all five cases, two different specimens: a blood sample and a skin swab were taken directly from the lesion, which were subjected to polymerase chain reaction (PCR) to test for OPV. PCR testing was performed to identify specific OPV DNA fragments of the Vgf, b9R and D11L genes. The tests were conducted in the Unit of Virology of the National Institute of Public Health in Warsaw, Poland. The results were described as positive or negative for the detection and differentiation of OPV. Detection of a specific Vgf fragment confirmed that the virus belonged to the Orthopoxviridae genus, while specific B9R and D11L fragments were markers for CPXV.

Table 1. Characteristics of children with diagnosed Orthopoxvirus infection

\begin{tabular}{llc}
\hline Parameter & \multicolumn{1}{c}{ Value } \\
\hline \multicolumn{2}{l}{ Number of children } & \multicolumn{1}{c}{5} \\
\hline Age [years] & & 2-13 (mean: 6.2) \\
\hline $\begin{array}{l}\text { Contact with } \\
\text { domestic animals }\end{array}$ & Cat & 5 \\
\cline { 2 - 3 } & Dog & 3 \\
\cline { 2 - 3 } & Monkey & 1 \\
\cline { 2 - 3 } & Cow & 1 \\
\cline { 2 - 3 } & Goat & 2 \\
\hline Symptoms & $\begin{array}{l}\text { Classical single } \\
\text { ulceration }\end{array}$ & 3 \\
\cline { 2 - 3 } & Disseminated & \\
& vesicular exanthema & \\
\hline
\end{tabular}

Serological tests for Cytomegalovirus, Herpesvirus (HSV) 1/2, Enteroviruses, Borrelia burgdorferi and Bartonella henselae and PCR for HSV were negative in all analysed children. Additionally, interferon- $\gamma$ release assays (IGRAs) were performed to exclude latent tuberculosis infection.

The laboratory investigations were a part of the routine diagnostic procedure. All procedures were documented in our patient record files.

\section{Results}

All analysed children with OPV infection were immunocompetent. They ranged in age from 2 to 13 years ( $M=6.6 \pm 2.33$ years). In their history, all patients had been in contact with animals, including a cat $(n=5)$, dog $(n=2)$, monkey $(n=1)$, cow $(n=1)$ and goat $(n=1)$. Three patients had close contact with more than one animal.

Regarding the clinical course, 2 children presented with high fever at the beginning of the disease course, after which they developed a single ulcer on the skin and local lymphadenopathy. The nodes were often painful, but the skin was not inflamed. Three other patients were in good general health, without fever or lymphadenopathy, and their skin lesions presented as a disseminated, vesicular rash.

In all patients, PCR tests for OPV were performed. The presence of the Vcf/Vgf gene was confirmed in material collected from skin lesions of all children, and was present in blood samples of 4 children. The B9R and d11L genes were present in skin samples of 2 children and blood samples of 2 children. Only 1 child showed positive results in both tests (Table 2).

The children were admitted after ineffective ambulatory therapy. Treatment with clindamycin, clarithromycin, trimethoprim/sulfamethoxazole and acyclovir were found to have no clinical effect.

The clinical course of OPV infection was prolonged. Before admission to our hospital, the patients were treated with antibiotics. One patient had a surgical excision of a part of the lesion.

After diagnosis, the patients were monitored in the outpatient clinic until the lesions had disappeared. The time from appearance of the first lesion until they disappeared was measured, with an average duration of 3 to 6 months.

\section{Discussion}

In the past, new descriptions of OPV infection in children emerged. The increasing number of infected children suggests that this disease is becoming more widespread than in the past $[5,9,10]$. Children represent one of the primary groups at higher risk of animal-to-human transmission of zoonotic infections [11]. The common behaviours of children, such as poor personal hygiene, close 
Table 2. Clinical characteristics of 5 patients presenting with an atypical form of $B$. henselae infection

\begin{tabular}{|c|c|c|c|c|c|c|c|c|c|c|}
\hline \multirow{2}{*}{$\begin{array}{l}\text { Age } \\
\text { [years]/ } \\
\text { Sex }\end{array}$} & \multirow[t]{2}{*}{ Clinical features } & \multirow{2}{*}{$\begin{array}{l}\text { Contact } \\
\text { with } \\
\text { animals }\end{array}$} & \multicolumn{3}{|c|}{$\begin{array}{l}\text { The PCR made } \\
\text { from blood }\end{array}$} & \multicolumn{3}{|c|}{$\begin{array}{l}\text { The PCR made from } \\
\text { the exceed material }\end{array}$} & \multirow{2}{*}{$\begin{array}{l}\text { Treatment } \\
\text { (without clinical } \\
\text { effect) }\end{array}$} & \multirow[t]{2}{*}{ Skin lesion pictures } \\
\hline & & & Vgf & b9R & d11L & Vgf & b9R & $\mathrm{d} 11 \mathrm{~L}$ & & \\
\hline $11 / M$ & $\begin{array}{l}\text { Fever, local } \\
\text { lymphadenopathy, } \\
\text { single necrotic } \\
\text { ulceration with } \\
\text { a black eschar on } \\
\text { the beard }\end{array}$ & $\begin{array}{l}\text { Cat, } \\
\text { monkey }\end{array}$ & ++ & + & + & + & + & + & $\begin{array}{l}\text { Trimethoprim/ } \\
\text { sulfamethoxazole, } \\
\text { clarithromycin, } \\
\text { surgical removing }\end{array}$ & \\
\hline $12 / \mathrm{M}$ & $\begin{array}{l}\text { Fever, single } \\
\text { necrotic lesion } \\
\text { on the eyebrow. } \\
\text { Cervical } \\
\text { lymphadenopathy }\end{array}$ & Cats & + & - & - & + & - & - & $\begin{array}{l}\text { Clindamycin, } \\
\text { acyclovir }\end{array}$ & \\
\hline 4/M & $\begin{array}{l}\text { Disseminated, } \\
\text { vesicular rash, } \\
\text { mild generalized } \\
\text { lymphadenopathy }\end{array}$ & $\begin{array}{l}\text { Cats, } \\
\text { cow, } \\
\text { racoon }\end{array}$ & + & - & - & ++ & + & + & Clarithromycin & \\
\hline $3 / M$ & $\begin{array}{l}\text { Disseminated, } \\
\text { vesicular rash }\end{array}$ & Cat & ++ & + & + & ++ & - & - & Clarithromycin & \\
\hline $2 / F$ & $\begin{array}{l}\text { Disseminated, } \\
\text { vesicular rash }\end{array}$ & Cat, dog & - & - & - & + & - & - & $\begin{array}{l}\text { Cefuroxime, } \\
\text { clindamycin, } \\
\text { cloxacillin }\end{array}$ & \\
\hline
\end{tabular}

contact with domestic animals, and a lack of parental supervision, increase the risk of different zoonotic infections, which are sometimes fatal [11, 12]. Additionally, animal transport and keeping exotic animals in the house can expose children to pathogens that are not specific to the domestic region. In our analysed group, all children had close contact with cats and three had contact with dogs. We also found patients who had come into contact with a cow, goat and monkey. All children had come into close contact with more than one animal.

The mean age of children included in our analysis indicates that this infection is prevalent in pre-school-aged patients; however, over time, lesions were being found in increasingly younger children. The last girl to be infected during our study period was only 2 years old. Such an observation emphasises that young children are at risk.

The classical clinical presentation of Orthopoxviridae infection is a papule which develops into an umbilicated vesicle surrounded by erythema. Before becoming ulcerated, the lesion passes through the haemorrhagic stage $[5,8]$. There is often only one lesion, but there have been few descriptions of multifocal necrosis during the course of infection $[9,13,14]$. The factors that are responsible for the generalised disease form are not yet known. It has been suggested that generalised and even lethal CPXV courses may be observed in immunocompromised patients or individuals with atopic or Darier's disease $[14,15]$. In our analysis, we found 3 children with a single lesion and two with disseminated lesions. In both groups, we confirmed the presence of OPV genetic material, but only in 3 children. Because of the small group of patients, we did not observe any connection between the type of Orthopoxviridae and the type of lesion. Furthermore, none of our patients were immunocompromised.

In our group of patients, only 2 children presented general symptoms like fever and myalgia. This observation differs from those of other authors $[5,8,14]$. More common symptoms, as described by other authors, include local lymphadenopathy and pain, especially in localised lesions [16-18].

For many years, OPV infections have been diagnosed by serological and biological methods in many countries. Nowadays, molecular diagnostic techniques, especially real-time PCR, are becoming more popular as they are fast and reliable, allowing this approach to be successfully applied to ORV and CPXV [19]. Orthopoxvirus infection can be identified using the conserved viral growth factor gene as the target for PCR. Further diagnostic procedures 
are directed at confirming CPXV by $6 \mathrm{kDa}$ intracellular viral protein (B9R) and temporal expression: late (d11L) [18]. Using three primers, we established CPXV infection in 3 children. Interestingly, even though 2 children presented with very similar skin lesions, we were only able to confirm OPV infection in both. This could be explained by the cause of the infection being another type of pox virus (MPXV or CMPV) or that CPXV was not detected by $P C R$ due to the genetic diversity of CPXV clades, related to drawbacks of PCR as a diagnostic method. Previous studies have shown that species of CPXV are a relatively diverse group within the OPV genus, and co-circulation of different CPXV clades within the same geographical region has been reported [19-22].

All analysed patients presented a history of ineffective antibiotic therapy and acyclovir treatment. This observation is similar to those of other authors. Antibiotics and antiviral drugs have only a preventive effect against bacterial superinfections, the same as local antiseptics, non-steroidal antirheumatic medicines and surgical debridement $[10,16]$. While the lesion is self-limiting, the infection requires time, sometimes many years, to be cured. Indeed, some medical substances have been tested for their efficacy in OPV therapy. One of these is cidofovir, which has broad-spectrum activity against DNA viruses including herpes-, adeno-, polyoma-, papillomaand poxviruses. Among poxviruses, cidofovir has shown in vitro activity against OPVs, including CPXV, MPXV, CMPV, VACV, variola virus (smallpox), molluscipox (molluscum contagiosum) and Parapoxvirus. The in vivo antipoxvirus activity of cidofovir has been demonstrated in different models of infection when the drug was administered in different ways (intraperitoneally, intranasally and topically). In humans, cidofovir has been successfully used for the treatment of recalcitrant molluscum contagiosum virus and orf virus in immunocompromised patients; however, its use is limited by nephrotoxic sideeffects $[23,24]$. The new therapy, which developed as a treatment for OPVs is brincidofovir (CMX001), a lipophilic nucleotide analogue. The substance has significantly higher potency than CDV against DNA viruses. In contrast to CDV, it is administered orally and has shown no risk of nephrotoxicity. Actually CMX001 treatment is tested on animal models: MPXV, rabbitpox virus for efficacy in smallpox epidemic [25]. The effect of the other substances, including oral tecovirimat, thiosemicarbazones, nucleoside and nucleotide analogues, interferon and interferon inducers, have also been tested, but none have been confirmed to be an effective treatment [26]. In the past, the smallpox vaccination might have provided cross-immunity against CPXV and other zoonotic OPVs [27].

In cases of unclear necrotising skin lesions in children, the primary diagnosis always includes bacterial dermatitis. However, if the patient has been in contact with animals, diagnosis of zoonotic OPV infection should also be considered.

\section{Conclusions}

Children and young adolescents seem to be the main important group of patients who can present with modern skin lesions caused by Orthopoxviridae because of the lack of immunity against smallpox and zoonotic OPVs.

\section{Conflict of interest}

The authors declare no conflict of interest.

\section{References}

1. Essbauer S, Pfeffer M, Meyer H. Zoonotic poxviruses. Vet Microbiol 2010; 140: 229-36.

2. Damon I. Poxviridae and their replication. Fields Virology Raven Press Ltd., New York 2007; 2079-81.

3. Abrahao JS, Lima LS, Assis FL, et al. Nested-multiplex PCR detection of Orthopoxvirus and Parapoxvirus directly from exanthematic clinical samples. Virol J 2009; 6: 140-5.

4. Nitsche A, Pauli G. Sporadic human cases of cowpox in Germany. Eurosurveillance 2007; 12: E070419.

5. Vestergaard L, Vinner L, Andersen KE, Fomsgaard A. Identification of cowpox infection in a 13-year-old Danish boy. Acta Derm Venereol 2008; 88: 188-90.

6. Tryland M, Sandvik T, Mehl R, et al. Serosurvey for Orthopoxviruses in rodents and shrews from Norway. J Wildl Dis 1998; 34: 240-50.

7. Herder V, Wohlsein P, Grunwald D, et al. Poxvirus infection in a cat with presumptive human transmission. Vet Dermatol 2011; 22: 220-4.

8. Eis-Hubinger AM, Gerritzen A, Schneweis KE, et al. Fatal cowpox-like virus infection transmitted by cat. Lancet 1990; 336: 880-4.

9. Miernik B, Casetti F, Panning M, et al. Multilocular facial necrosis in a young boy: a quiz. Acta Derm Venereol 2017; 97 : 299-301.

10. Talarek E, Marczyńska M. Cowpox virus infection. N Engl J Med 2018; 378: 181.

11. Mazur-Melewska K, Jończyk-Potoczna K, Mania A. The significance of Bartonella henselae bacterias for oncological diagnosis in children. Infect Agent Cancer 2015; 10: 1-7.

12. Mazur-Melewska K, Jonczyk-Potoczna K, Kemnitz P, et al. Pulmonary presentation of Toxocara sp. infection in children. Pneumonol Alergol Pol 2015; 83: 250-5.

13. Grönemeyer LL, Baltzer A, Broekaert A, et al. Generalised cowpox virus infection. Lancet 2017; 390: 1769.

14. Haase O, Moser A, Rose C, et al. Generalized cowpox infection in a patient with Darier disease. Br J Dermatol 2011; 164: 1116-8.

15. Pelkonen PM, Tarvainen K, Hynninen A, et al. Cowpox with Severe Generalized Eruption, Finland. Emerg Infect Dis 2003; 9: 1458-61.

16. Pahlitzsch R, Hammarin AL, Widell A. A case of facial cellulitis and necrotizing lymphadenitis due to cowpox virus infection. Clin Infect Dis 2006; 43: 737-42.

17. Hobi S, Mueller RS, Hill M, et al. Neurogenic inflammation and colliquative lymphadenitis with persistent orthopox 
virus DNA detection in a human case of cowpox virus infection transmitted by a domestic cat. Br J Dermatol 2015; 173: 535-9.

18. Wienecke R, Wolff H, Schaller M, et al. Cowpox virus infection in an 11-year-old girl. J Am Acad Dermatol 2000; 42: 892-94.

19. Gavrilova EV, Shcherbakov DN, Maksyutov RA, Shchelkunov SN. Development of real-time PCR assay for specific detection of cowpox virus. J Clin Virol 2010; 49: 37-40.

20. Carroll DS, Emerson GL, Li Y, et al. Chasing jenner's vaccine: revisiting cowpox virus classification. PLoS One 2011; 6;: e23086.

21. Franke A, Pfaff F, Jenckel M, et al. Classification of Cowpox viruses into several distinct clades and identification of a novel lineage. Viruses 2017; 10: E142.

22. Meyer H, Damon IK, Esposito JJ. Orthopoxvirus diagnostics. Methods Mol Biol 2004; 269: 119-34.

23. Andrei G, Snoeck R. Cidofovir activity against Poxvirus infections. Viruses 2010; 2: 2803-30.

24. De Clercq E. Cidofovir in the treatment of poxvirus infections. Antiviral Res 2002; 55: 1-13.

25. Rice AD, Adams MM, Lampert B, et al. Efficacy of CMX001 as a prophylactic and presymptomatic antiviral agent in New Zealand white rabbits infected with rabbitpox virus, a model for orthopoxvirus infections of humans. Viruses 2011; 3: 63-82.

26. Smee DF, Sidwell RW. A review of compounds exhibiting anti-orthopoxvirus activity in animal models. Antiviral Res 2003; 57: 41-52

27. Vogel S, Sárdy M, Glos K, et al. The Munich outbreak of cutaneous cowpox infection: transmission by infected pet rats. Acta Derm Venereol 2012; 92: 126-31. 